\title{
SYSTEMATIC LITERATURE REVIEW: IMPLEMENTASI PENDEKATAN STEM (MANFAAT DAN TANTANGAN) DI INDONESIA
}

\author{
Fika Ariani Thovawira ${ }^{1^{*}}$, Islamiani Safitri ${ }^{2}$,Supartik ${ }^{3}$ \\ Nova Nadila Saputri Sitompul ${ }^{4}$,Ikke Anggriani ${ }^{5}$ \\ 1,2,3,4,5 Universitas Labuhanbatu \\ *Corresponding Author, E-mail: fikaarianithovawira.18@gmail.com \\ Received: 11 Juli 2020: Revised: 15 September 2020 ; Accepted: 30 September 2020
}

\begin{abstract}
ABSTRAK
Untuk menghadapi tantangan pendidikan masa kini dibutuhkan keterampilan seperti keterampilan berpikir,keterampilan analisis,dan juga keterampilan dalam berkreativitas. Pendidikan dengan pendekatan sains, teknologi, teknik dan matematika yaitu (STEM) menjadi problematika di dunia pendidikan di Indonesia saat ini. Implementasi pendekatan STEM yang dilakukan pada kegiatan belajar memotivasi siswa untuk mampu mengelola dan melakukan integritas melalui teknologi, serta menerapkan pengetahuan dalam kehidupan sehari-hari. Tujuan dari penelitian ini untuk mengetahui implementasi pendekatan STEM (manfaat dan tantangan) di Indonesia dengan menggunakan metode Systematic Literatur Review (SLR). Metode SLR digunakan untuk mengidentifikasi, mengkaji, mengevaluasi, dan menafsirkan semua penelitian yang tersedia dengan bidang topik fenomena yang menarik, dengan pertanyaan penelitian tertentu yang relevan. Penggunaan Metode SLR dapat mengidentifikasi jurnal secara sistematis, yang pada setiap prosesnya mengikuti langkah-langkah atau protokol yang telah ditetapkan. Jumlah artikel yang ditemukan sebanyak 56 artikel dengan karakteristik sesuai target penelitian, kemudian melalui proses screening diambil 30 artikel, setelah itu tahapan selanjutnya kriteria inklusi eksklusi sehingga ditemukan 25 artikel untuk selanjutnya dilakukan review. Hasil penelitian menunjukkan bahwa implementasi pendekatan STEM di Indonesia memiliki pengaruh yang cukup baik terhadap terhadap cara berpikir kreatif siswa, LKS, buku siswa dan menghadapi revolusi industri 4.0 ,literasi matematis dan implementasi STEM dengan robotika, dan juga persepsi guru terhadap pembelajaran STEM.
\end{abstract}

Kata Kunci: Implementasi, STEM ,Systematic Literatur Review.

\begin{tabular}{l} 
ABSTRACT \\
To face the challenges of today's education requires skills such as thinking skills, analytical skills, \\
and also skills in creativity. Education with the approach of science, technology, engineering and \\
mathematics (STEM) is a problem in the world of education in Indonesia today. The \\
implementation of the STEM approach that is carried out in learning activities motivates students \\
to be able to manage and carry out integrity through technology, as well as apply knowledge in \\
everyday life. The purpose of this study was to determine the implementation of the STEM \\
approach (benefits and challenges) in Indonesia using the Systematic Literature Review (SLR) \\
method. The SLR method is used to identify, review, evaluate, and interpret all available research \\
on the topic area of the phenomenon of interest, with specific relevant research questions. The use \\
of the SLR method can systematically identify journals, which in each process follow \\
predetermined steps or protocols. The number of articles found was 56 articles with the \\
characteristics according to the research target, then through the screening process 30 articles \\
were taken, after that the next stage was the exclusion criteria for exclusion so that 25 articles \\
were found for further review. The results showed that the implementation of the STEM approach \\
in Indonesia had a fairly good effect on the creative thinking of students, student worksheets, \\
student books and facing the industrial revolution 4.0 , mathematical literacy and STEM \\
implementation with robotics, as well as teachers' perceptions of STEM learning. \\
Keywords: Implementation, STEM, Systematic Literature Review. \\
How to Cite: Thovawira, F, A., dkk. (2020). Systematic Literature Review: Implementasi \\
Pendekatan STEM (Manfaat Dan Tantangan) Di Indonesia. Histogram: Jurnal Pendidikan \\
Matematika, 4(2), 355-371, doi: http://dx.doi.org/10.31100/histogram.v4i2.682 \\
Permalink/DOI: http://dx.doi.org/10.31100/histogram.v4i2.682 \\
\hline
\end{tabular}


Histogram: Jurnal Pendidikan Matematika, 4 (2), 2020 - 356

Fika Ariani Thovawira ${ }^{{ }^{*}}$, Islamiani Safitri ${ }^{2}$,Supartik 3

Nova Nadila Saputri Sitompul 4 ,Ikke Anggriani 5

\section{PENDAHULUAN}

Pada abad 21, sangat dibutuhkan keterampilan menganalisis, pemecahan masalah, berpikir kritis dan berpikir kreatif. Keterampilan penting dimiliki siswa agar dapat menghubungkan konsep dan materi sehingga siswa bisa menyelesaikan permasalahan yang terjadi di kelas (Beers,2011). Salah satu upaya untuk menumbuhkan keterampilan tersebut adalah dengan melakukan inovasi terhadap aktivitas pembelajaran yang menarik perhatian siswa. Pembelajaran berbasis sains, teknologi, teknik dan matematika sangat disarankan guna tercapainya keterampilan-keterampilan yang dibutuhkan pada masa kini. Pendekatan STEM sebagai suatu metode belajar yang mengaplikasikan pembelajaran dalam konteks pemecahan masalah. Keunggulan pendekatan STEM dalam kegiatan belajar adalah memberikan latihan kepada siswa untuk mampu mengintegrasikan semua aspek, meliputi aspek kognitif, afektif dan psikomotorik siswa.

Pendekatan STEM merupakan integrasi dari pembelajaran sains, teknologi, teknik, dan matematika. STEM dapat berkembang apabila dikaitkan dengan lingkungan, sehingga terwujud sebuah pembelajaran yang menghadirkan dunia nyata yang dialami siswa dalam kehidupan sehari-hari. Hal ini berarti melalui pendekatan STEM siswa tidak hanya sekedar menghafal konsep saja, tetapi lebih kepada bagaimana siswa mengerti dan memahami konsep-konsep sains dan kaitanya dalam kehidupan sehari-hari. Sehingga dengan implementasi STEM siswa dapat berpikir kritis, kreatif dan inovatif.

Disiplin ilmu dalam pembelajaran yang menerapkan pendekatan STEM juga merambah ke berbagai bidang termasuk sosial dan ekonomi, (Sari, 2017). Berdasarkan hal ini, Indonesia pun harus mempersiapkan generasi yang dapat bersaing dalam disiplin STEM. Dengan demikian hal tersebut seiring dengan tujuan kurikulum 2013 yaitu mengutamakan proses keterampilan berpikir kritis,kreatif, dan inovatif. Pembelajaran dalam kurikulum 2013 menerapkan kegiatan pembelajaran dengan penilaian yang absah, sehingga tercapai kompetensi dalam ranah kognitif,afektif dan psikomotorik. Ratifikasi aktivitas belajar pada kurikulum 2013 diterapkan dengan pendekatan yang saintifik, (Istiqomah, 2019).

Pada revolusi industri 4.0 banyak mempengaruhi aspek kehidupan manusia salah satunya dalam pendidikan. Upaya menjawab tantangan ini pemerintah RI melakukan perubahan kurikulum berbasis konten menjadi kurikulum berbasis kompetensi. Selain itu, pemerintah juga telah menyusun standar pendidikan nasional dalam hal sarana dan prasarana. Menurut Peraturan Kementerian Pendidikan dan Kebudayaan nomor 26 tahun 
Histogram: Jurnal Pendidikan Matematika, 4 (2), 2020 - 357

Fika Ariani Thovawira ${ }^{*}$, Islamiani Safitri ${ }^{2}$,Supartik 3

Nova Nadila Saputri Sitompul 4 ,Ikke Anggriani 5

2016 perihal sarana dan prasarana mengatur tentang bahan ajar yang tersedia di sekolah. Bahan ajar adalah seperangkat bahan mengenai materi pembelajaran, metode dan evaluasi yang disusun dengan sistematis dan menarih sehingga tercapai tujuan pembelajaran(Lestari, 2013).

Beberapa impelementasi pendekatan STEM di Indonesia adalah berpikir kreatif siswa, LKS, buku siswa, menghadapi revolusi industri 4.0, implementasi STEM dengan robotika, dan persepsi guru terhadap pendekatan STEM. Penelitian ini menggunakan metode sistematik literatur review yang melalui proses pencarian literatur dengan publikasi dari tahun 2015-2020. Dengan kriteria inklusi dan eksklusi diperoleh 25 artikel kemudian dianalisis manfaat dan tantangan pendekatan STEM di Indonesia.

\section{METODE PENELITIAN}

Metode penelitian ini menggunakan metode Systematic Literatur Review (SLR). Metode SLR dapat mengidentifikasi jurnal secara sistematis, yang pada setiap prosesnya mengikuti langkah-langkah atau protokol yang telah ditetapkan. Langkah awal dalam metode SLR adalah menentukan objek penelitian. Dalam penelitian ini objek penelitiannya merupakan implementasi STEM. Pengambilan objek penelitian berdasarkan pada beberapa alasan. Pertama, terdapat perubahan dalam implementasi STEM yang sebelumnya jarang digunakan dan kini mulai banyak digunakan untuk meningkatkan mutu pembelajaran di Indonesia. Kedua, pengembangan implementasi STEM dapat dilakukan di berbagai bidang, antara lain sains, teknologi, teknik, dan matematika. Ketiga, implementasi STEM memiliki metode-metode yang beragam.

Langkah metode SLR selanjutnya adalah menentukan pertanyaan penelitian (Research Question :RQ) yaitu pertanyaan yang dibuat berdasarkan kebutuhan dari topik yang dipilih. Pertanyaan penelitian ini terdiri dari 5 kriteria, RQ1 sampai dengan RQ5. Pertama (RQ1) tentang implementasi STEM untuk meningkatkan berpikir kreatif siswa, kedua (RQ2) tentang implementasi STEM dapat digunakan dalam pengembangan lembar kerja siswa (LKS), ketiga (RQ3)tentang implementasi STEM dapat dilakukan dalam pengembangan buku siswa dan menghadapi pembelajaran abad 21, keempat (RQ4) tentang persepsi guru terhadap pembelajaran STEM, kelima (RQ5) tentang implementasi STEM dengan robotika.

Selanjutnya langkah proses pencarian (Search Process), dengan menggunakan search engine yang dilakukan untuk mendapatkan sumber penelitian yang relevan dan sebagai bahan referensi, dalam hal ini diperoleh 56 artikel yang sesuai dengan objek penelitian. Terdapat 30 diantaranya yang memenuhi kriteria pertanyaan penelitian 
Histogram: Jurnal Pendidikan Matematika, 4 (2), 2020 - 358

Fika Ariani Thovawira ${ }^{{ }^{*}}$, Islamiani Safitri ${ }^{2}$,Supartik 3

Nova Nadila Saputri Sitompul 4 ,Ikke Anggriani 5

(Research Question). Dari hasil proses pencarian langkah metode SLR berikutnya adalah kriteria inklusi dan eksklusi dilakukan untuk mengambil keputusan apakah data layak dalam penelitian SLR atau tidak yang dipilih melalui tiga kriteria.Pertama, klasifikasi data pada tahun terbit dengan rentang waktu 2015-2020. Kedua, data yang diperoleh melalui pencarian search engine harus terindeks SINTA. Ketiga, klasifikasi data berhubungan dengan implementasi STEM di Indonesia.

Setelah dilakukan klasifikasi berdasarkan kriteri inklusi dan eksklusi langkah selanjutnya dalam metode SLR adalah penilaian kualitas (Quality Assessment: QA). Dalam penilaian kualitas (QA) terdiri atas 3 kriteria. Kriteria pertama (QA1)," Apakah artikel diterbitkan pada jurnal dalam rentang waktu 2015-2020?”. Kriteria kedua (QA2),"Apakah artikel mengandung isi tentang implementasi STEM?". Dan kriteria ketiga (QA3),"Apakah artikel mendeskripsikan metode yang digunakan terkait implementasi STEM di Indonesia?”. Hasil penelusuran artikel berdasarkan tahapan QA, selanjutnya dianalisis lagi untuk mengkaji manfaat dan tantangan implementasi STEM di Indonesia. Analisis data dilakukan untuk menunjukkan implementasi STEM terhadap berpikir kreatif siswa, pengembangan lembar kerja siswa (LKS), pengembangan buku siswa menghadapi revolusi industri 4.0 dalam pembelajaran abad 21,persepsi guru terhadap pembelajaran STEM,dan robotika. Tahapan atau langkah terakhir metode SLR adalah penyimpanan laporan (Deviation From Protokol)dilakukan untuk mengkaji identifikasi implementasi STEM (manfaat dan tantangan) di Indonesia guna menjawab pertanyaan penelitian,mengumpulkan artikel untuk menjawab manfaat dan tantangan implementasi STEM di Indonesia, serta memperluas deskrispsi tentang SLR pada penelitian ini.

Dengan demikian, dari jumlah artikel yang ditemukan sebanyak 56 artikel dengan karakteristik sesuai target penelitian. Kemudian melalui proses screening (RQ) diambil 30 artikel. Setelah itu tahapan selanjutnya kriteria inklusi eksklusi sehingga ditemukan 25 artikel untuk selanjutnya dilakukan review. Hal ini dapat dilihat dalam tabel 1 pada bagian hasil penelitian.

\section{HASIL DAN PEMBAHASAN}

\section{A. Hasil Penelitian}

Berdasarkan hasil klasifikasi artikel pada kategori penelitian "Impelementasi STEM di Indonesia"diperoleh 56 artikel yang cocok dengan topik penelitian, kemudian dilakukan screening terkait kesamaan judul artikel. Setelah proses screening terdapat 30 artikel dengan judul yang sama. Selanjutnya 30 artikel discreening berdasarkan 
Histogram: Jurnal Pendidikan Matematika, 4 (2), 2020 - 359

Fika Ariani Thovawira ${ }^{{ }^{*}}$, Islamiani Safitri ${ }^{2}$,Supartik 3

Nova Nadila Saputri Sitompul 4 ,Ikke Anggriani 5

kesesuaian syarat dengan kriteria inklusi dan kriteria eksklusi maka diperoleh 25 artikel. Berikut strategi pencarian literatur pada tabel 1 .

Tabel 1. Strategi pencarian literature berdasarkan RQ,Inklusi dan Eksklusi

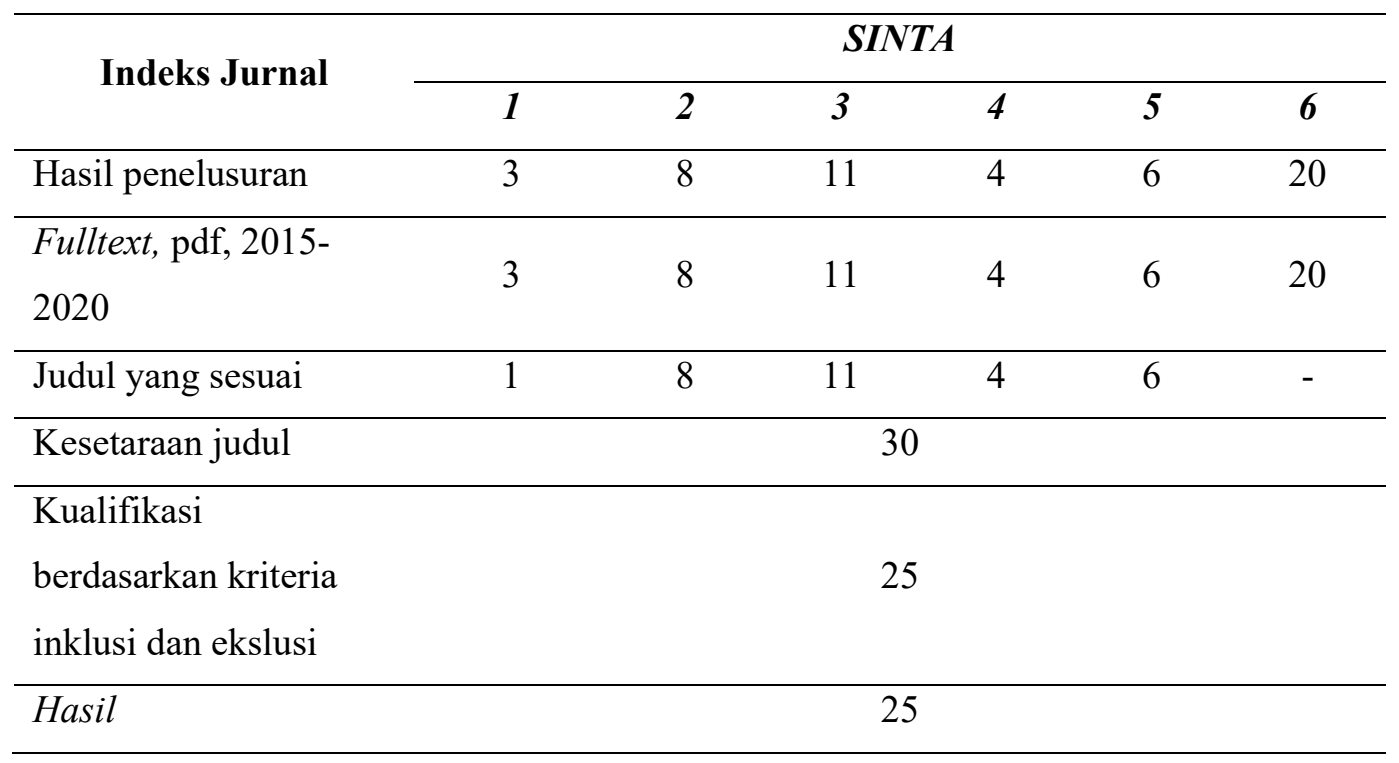

Pada tabel di atas, proses pencarian artikel yang sesuai dengan objek penelitian diambil dari Google Scholar dan diperoleh 56 artikel. Sebanyak 52 artikel terindeks Science and Technology Index (SINTA) yang dianalisis berdasarkan jurnal melalui search engine pada website www.sinta.ristekbrin.go.id. Sementara itu, 4 artikel belum terindeks SINTA, sehingga artikel tersebut tidak termasuk dalam pencarian literatur. Artikel berdasarkan eligibility memiliki beberapa penelitian yang dilakukan dari berbagai provinsi di Indonesia. Hasil analisis pada 25 artikel terdapat 14 artikel dengan desain quantitatif descriptive, 5 artikel dengan desain artikel review, 4 artikel dengan desain quasi experiment dan 2 artikel dengan pendekatan deskriptif. Ditinjau dari segi pengkajian kualitas studi dari 25 artikel diekstraksi data. Kemudian ekstraksi data dibuat dengan melakukan analisis data sesuai nama penulis, judul, metode, tujuan dan hasil penelitian yang dikelompokkan dapat dilihat dalam tabel 2 berikut:

Tabel 2. Langkah Akhir SLR : penyimpanan laporan (Deviation From Protokol)

\begin{tabular}{|c|c|c|c|c|c|}
\hline No & $\begin{array}{c}\text { Penulis } \\
\text { dan } \\
\text { Tahun }\end{array}$ & Topik & $\begin{array}{l}\text { Nama } \\
\text { Jurnal }\end{array}$ & $\begin{array}{l}\text { Tujuan } \\
\text { Penelitian }\end{array}$ & $\begin{array}{c}\text { Hasil } \\
\text { Penelitian }\end{array}$ \\
\hline 1 & $\begin{array}{c}\text { Fitria } \\
\text { Sarnita,dkk. } \\
2019\end{array}$ & $\begin{array}{l}\text { Pengembangan Perangkat } \\
\text { Pembelajaran Model PBL } \\
\text { Berbasis STEM Untuk } \\
\text { Melatih Keterampilan } \\
\text { Berfikir Kreatif Siswa }\end{array}$ & $\begin{array}{c}\text { Jurnal } \\
\text { Pendidikan } \\
\text { MIPA }\end{array}$ & $\begin{array}{c}\text { Melatih } \\
\text { keterampilan } \\
\text { berpikir kreatif } \\
\text { dengan } \\
\text { pendekatan STEM }\end{array}$ & $\begin{array}{l}\text { LKS berbasis } \\
\text { STEM }\end{array}$ \\
\hline
\end{tabular}


Histogram: Jurnal Pendidikan Matematika, 4 (2), 2020 - 360

Fika Ariani Thovawira ${ }^{{ }^{*}}$, Islamiani Safitri ${ }^{2}$,Supartik 3

Nova Nadila Saputri Sitompul 4 ,Ikke Anggriani 5

\begin{tabular}{|c|c|c|c|c|c|}
\hline No & $\begin{array}{c}\text { Penulis } \\
\text { dan } \\
\text { Tahun }\end{array}$ & Topik & $\begin{array}{l}\text { Nama } \\
\text { Jurnal }\end{array}$ & $\begin{array}{c}\text { Tujuan } \\
\text { Penelitian }\end{array}$ & $\begin{array}{c}\text { Hasil } \\
\text { Penelitian }\end{array}$ \\
\hline & & Tuna Netra & & $\begin{array}{c}\text { pada siswa tuna } \\
\text { netra }\end{array}$ & \\
\hline 2 & $\begin{array}{c}\text { Rifka } \\
\text { Annisa, } \\
\text { Dkk. } 2018\end{array}$ & $\begin{array}{c}\text { Peningkatan Kemampuan } \\
\text { Berpikir Kreatif Siswa } \\
\text { dengan Menggunakan } \\
\text { Model PBL Berbasis } \\
\text { STEAM Pada Materi } \\
\text { Asam Dan Basa Di SMAN } \\
\text { 11 Kota Jambi }\end{array}$ & $\begin{array}{l}\text { Jurnal of } \\
\text { the } \\
\text { Indonesia } \\
\text { society of } \\
\text { integrated } \\
\text { chemistry }\end{array}$ & $\begin{array}{l}\text { Meningkatkan } \\
\text { kreativitas siswa }\end{array}$ & $\begin{array}{c}\text { Peningkatan } \\
\text { kemampuan } \\
\text { berpikir kreatif } \\
\text { dengan STEM } \\
\text { yang pada } \\
\text { siswa di } \\
\text { SMAN 11 } \\
\text { Kota Jambi } \\
\end{array}$ \\
\hline 3 & $\begin{array}{l}\text { Siswanto, } \\
2018\end{array}$ & $\begin{array}{c}\text { Keefektifan Pembelajaran } \\
\text { Fisika dengan Pendekatan } \\
\text { STEM untuk } \\
\text { Meningkatkan Kreativitas } \\
\text { Mahasiswa }\end{array}$ & $\begin{array}{c}\text { Jurnal } \\
\text { Penelitian } \\
\text { Pembelajar } \\
\text { an Fisika }\end{array}$ & $\begin{array}{l}\text { Meningkatkan } \\
\text { kreativitas } \\
\text { mahasiswa dalam } \\
\text { pembelajaran } \\
\text { Fisika }\end{array}$ & $\begin{array}{c}\text { Menunjukkan } \\
\text { bahwa } \\
\text { pembelajaran } \\
\text { fisika dengan } \\
\text { pendekatan } \\
\text { STEM adalah } \\
\text { efektif untuk } \\
\text { meningkatkan } \\
\text { kreativitas } \\
\text { mahasiswa } \\
\text { dengan kriteria } \\
\text { sedang. }\end{array}$ \\
\hline 4 & $\begin{array}{c}\text { Indri } \\
\text { Octaviyani, } \\
\text { dkk. } 2020\end{array}$ & $\begin{array}{c}\text { Peningkatan Kemampuan } \\
\text { Berpikir Kreatif } \\
\text { Mamtematis Siswa Melalui } \\
\text { Model Project-Based } \\
\text { Learning dengan STEM }\end{array}$ & $\begin{array}{l}\text { Journal on } \\
\text { Mathemati } \\
\text { cs } \\
\text { Education } \\
\text { Research }\end{array}$ & $\begin{array}{c}\text { Meningkatkan } \\
\text { kemampuan } \\
\text { berpikir kreatif } \\
\text { dengan PBL } \\
\text { dengan pendekatan } \\
\text { STEM }\end{array}$ & $\begin{array}{l}\text { Peningkatan } \\
\text { kemampuan } \\
\text { berpikir kreatif } \\
\text { matematis } \\
\text { siswa adalah } \\
0,76 \text { (kategori } \\
\text { tinggi). } \\
\end{array}$ \\
\hline 5 & $\begin{array}{c}\text { Siti } \\
\text { Wahyuning } \\
\text { si,dkk } 2020\end{array}$ & $\begin{array}{c}\text { Efek Metode STEAM } \\
\text { pada Kreatifitas Anak } \\
\text { Usia 5-6 Tahun }\end{array}$ & $\begin{array}{c}\text { Jurnal } \\
\text { Pendidikan } \\
\text { Anak Usia } \\
\text { Dini }\end{array}$ & $\begin{array}{c}\text { Menguji } \\
\text { efektifitas STEM } \\
\text { sada pembelajaran } \\
\text { anak usia 5-6 } \\
\text { tahun } \\
\end{array}$ & $\begin{array}{l}\text { Meningkatkan } \\
\text { kreativitas } \\
\text { anak dalam } \\
\text { pemecahan } \\
\text { masalah } \\
\end{array}$ \\
\hline 6 & $\begin{array}{l}\text { Sri Endang } \\
\text { Supriyatun. } \\
2019\end{array}$ & $\begin{array}{c}\text { Implementasi } \\
\text { Pembelajaran STEM pada } \\
\text { Materi Fungsi Kuadrat }\end{array}$ & $\begin{array}{l}\text { Research } \\
\text { gate }\end{array}$ & $\begin{array}{l}\text { Mengetahui } \\
\text { implementasi } \\
\text { STEM pada } \\
\text { materi fungsi } \\
\text { kuadrat }\end{array}$ & $\begin{array}{c}\text { Terdapat } \\
\text { pengaruh } \\
\text { penerapan } \\
\text { pembelajaran } \\
\text { dengan } \\
\text { pendekatan } \\
\text { STEM pada } \\
\text { materi fungsi } \\
\text { kuadrat } \\
\end{array}$ \\
\hline
\end{tabular}


Histogram: Jurnal Pendidikan Matematika, 4 (2), 2020 - 361

Fika Ariani Thovawira ${ }^{{ }^{*}}$, Islamiani Safitri ${ }^{2}$,Supartik 3

Nova Nadila Saputri Sitompul 4 ,Ikke Anggriani 5

\begin{tabular}{|c|c|c|c|c|c|}
\hline No & $\begin{array}{c}\text { Penulis } \\
\text { dan } \\
\text { Tahun }\end{array}$ & Topik & $\begin{array}{l}\text { Nama } \\
\text { Jurnal }\end{array}$ & $\begin{array}{l}\text { Tujuan } \\
\text { Penelitian }\end{array}$ & $\begin{array}{c}\text { Hasil } \\
\text { Penelitian }\end{array}$ \\
\hline 7 & $\begin{array}{c}\text { Rizki } \\
\text { Hananan } \\
\text { Sari. } 2017\end{array}$ & $\begin{array}{c}\text { Pengaruh Implementasi } \\
\text { Pembelajaran STEM } \\
\text { Terhadap Persepsi, Sikap, } \\
\text { dan Kreativitas Siswa }\end{array}$ & $\begin{array}{l}\text { Prosidings } \\
\text { eminar } \\
\text { Nasional } \\
\text { MIPA III }\end{array}$ & $\begin{array}{l}\text { Pengaruh } \\
\text { implementasi } \\
\text { STEM. }\end{array}$ & $\begin{array}{c}\text { Pembelajaran } \\
\text { STEM sudah } \\
\text { menuju taraf } \\
\text { keefektifan } \\
\text { dalam } \\
\text { pendidikan di } \\
\text { Indonesia } \\
\end{array}$ \\
\hline 8 & $\begin{array}{l}\text { Aeniyatul } \\
\text { Istiqomah. } \\
2019\end{array}$ & $\begin{array}{l}\text { Implementasi Strategi I- } \\
\text { STEM PADA } \\
\text { Pembelajaran IPA } \\
\text { terhadap Kemampuan } \\
\text { Berpikir Kreatif dan } \\
\text { Karakter Konservasi Siswa }\end{array}$ & & $\begin{array}{l}\text { Pengaruh I-STEM } \\
\text { Jada pembelajaran } \\
\text { IPA agar siswa } \\
\text { berpikir kreatif } \\
\text { dan karakter } \\
\text { konservasi }\end{array}$ & $\begin{array}{c}\text { Terdapat } \\
\text { pengaruh yang } \\
\text { signifikan } \\
\text { terhadap } \\
\text { berpikir kreatif } \\
\text { dan } \\
\text { peningkatan } \\
\text { karakter } \\
\text { konservasi } \\
\text { dengan model } \\
\text { I-STEM. }\end{array}$ \\
\hline 9 & $\begin{array}{c}\text { Ani } \\
\text { Ismayani. } \\
2016\end{array}$ & $\begin{array}{l}\text { Pengaruh Penerapan } \\
\text { STEM Project Based } \\
\text { Learning Terhadap } \\
\text { Kreativitas Matematis } \\
\text { Siswa SMK }\end{array}$ & $\begin{array}{l}\text { Indonesian } \\
\text { Digital } \\
\text { Journal of } \\
\text { Mathemati } \\
\text { cs and } \\
\text { Education }\end{array}$ & $\begin{array}{l}\text { Meningkatkan } \\
\text { keterampilan } \\
\text { serpikir matematis } \\
\text { dan kreatif }\end{array}$ & $\begin{array}{l}\text { Terdapat } \\
\text { peningkatan } \\
\text { berpikir } \\
\text { matematis } \\
\text { dengan } \\
\text { penerapan } \\
\text { STEM dengan } \\
\text { model PBL }\end{array}$ \\
\hline 10 & $\begin{array}{l}\text { Woro } \\
\text { Sumarni, } \\
\text { NanikWijay } \\
\text { ati, Sri } \\
\text { Supanti. } \\
2019\end{array}$ & $\begin{array}{c}\text { Kemampuan Kognitif dan } \\
\text { Berpikir Kreatif Siswa } \\
\text { Melalui Pembelajaran } \\
\text { Berbasis Proyek } \\
\text { Berpendekatan STEM }\end{array}$ & $\begin{array}{c}\text { Jurnal } \\
\text { Pembelajar } \\
\text { an Kimia }\end{array}$ & $\begin{array}{c}\text { Analisis penerapan } \\
\text { STEM untuk } \\
\text { meningkatkan } \\
\text { kemampuan } \\
\text { kognitif }\end{array}$ & $\begin{array}{l}\text { Tercapainya } \\
\text { kemampuan } \\
\text { kognitif dan } \\
\text { berpikir kreatif } \\
\text { siswa dengan } \\
\text { PBL melalui } \\
\text { pendekatan } \\
\text { STEM }\end{array}$ \\
\hline 11 & $\begin{array}{l}\text { Quratulaini. } \\
2019\end{array}$ & $\begin{array}{l}\text { Pengembangan LKS IPA } \\
\text { berbasis STEM untuk } \\
\text { meningkatkan kemampuan } \\
\text { berpikir kreatif dan hasil } \\
\text { belajar siswa SMP/MTS }\end{array}$ & Thesis & $\begin{array}{c}\text { Meninjau } \\
\text { kevalidan dan } \\
\text { keefektivan } \\
\text { pembelajaran } \\
\text { berbasis STEM } \\
\text { dalam } \\
\text { meningkatkan } \\
\text { pemikiran kreatif }\end{array}$ & $\begin{array}{c}\text { LKS IPA } \\
\text { berbasis STEM }\end{array}$ \\
\hline 12 & $\begin{array}{c}\text { Muthmainn } \\
\text { ah, Rahmah } \\
\text { Johar, dan }\end{array}$ & $\begin{array}{l}\text { Kemampuan Siswa SMP } \\
\text { Membat Denah melalui } \\
\text { Pendekatan STEM Pada } \\
\end{array}$ & $\begin{array}{c}\text { Jurnal } \\
\text { Ilmiah } \\
\text { Mahasiswa } \\
\end{array}$ & $\begin{array}{c}\text { Menganalisis } \\
\text { kemampuan siswa } \\
\text { membuat denah }\end{array}$ & $\begin{array}{c}\text { Tercapai } \\
\text { kemampuan } \\
\text { kognitif siswa } \\
\end{array}$ \\
\hline
\end{tabular}

ISSN: 2549-6700 (print), ISSN: 2549-6719 (online) 
Histogram: Jurnal Pendidikan Matematika, 4 (2), 2020 - 362

Fika Ariani Thovawira ${ }^{{ }^{*}}$, Islamiani Safitri ${ }^{2}$,Supartik 3

Nova Nadila Saputri Sitompul 4 ,Ikke Anggriani 5

\begin{tabular}{|c|c|c|c|c|c|}
\hline No & $\begin{array}{c}\text { Penulis } \\
\text { dan } \\
\text { Tahun }\end{array}$ & Topik & $\begin{array}{l}\text { Nama } \\
\text { Jurnal }\end{array}$ & $\begin{array}{c}\text { Tujuan } \\
\text { Penelitian }\end{array}$ & $\begin{array}{c}\text { Hasil } \\
\text { Penelitian }\end{array}$ \\
\hline & $\begin{array}{c}\text { Anwar. } \\
2019\end{array}$ & Materi Perbandingan & $\begin{array}{c}\text { Pendidikan } \\
\text { Matematik } \\
\text { a }\end{array}$ & dengan & $\begin{array}{c}\text { dengan } \\
\text { pendekatan } \\
\text { STEM }\end{array}$ \\
\hline 13 & $\begin{array}{l}\text { Ratri Sekar } \\
\text { Pertiwi, } \\
\text { dkk. } 2018\end{array}$ & $\begin{array}{l}\text { Efektivitas LKS STEM } \\
\text { Untuk Melatih } \\
\text { Keterampilan Berpikir } \\
\text { Kreatif Siswa }\end{array}$ & & $\begin{array}{c}\text { Meninjau } \\
\text { keefektivan LKS } \\
\text { berbasis STEM } \\
\text { dalam } \\
\text { meningkatkan } \\
\text { pemikiran kreatif } \\
\text { siswa } \\
\end{array}$ & $\begin{array}{l}\text { Tercapai } \\
\text { efektivitas } \\
\text { LKS dalam } \\
\text { melatih } \\
\text { berpikir kreatif } \\
\text { siswa }\end{array}$ \\
\hline 14 & $\begin{array}{l}\text { Oktaviani } \\
\text { Putri } \\
\text { Sukmagati, } \\
\text { dkk. } 2020\end{array}$ & $\begin{array}{c}\text { Pengembangan Lembar } \\
\text { Kerja Siswa Berbasis } \\
\text { STEMuntuk } \\
\text { Meningkatkan } \\
\text { Kemampuan Berpikir } \\
\text { Kreatif Siswa SMP }\end{array}$ & $\begin{array}{c}\text { Unnes } \\
\text { Physics } \\
\text { Education } \\
\text { Journal }\end{array}$ & $\begin{array}{c}\text { Mengembangkan } \\
\text { LKS dengan } \\
\text { pendekatan STEM } \\
\text { untuk } \\
\text { meningkatkan } \\
\text { pemikiran kreatif }\end{array}$ & $\begin{array}{c}\text { Tercapai } \\
\text { keberhasilan } \\
\text { pada pretest } \\
\text { dan post test } \\
\text { dari } \\
\text { pengembangan } \\
\text { LKS berbasis } \\
\text { STEM }\end{array}$ \\
\hline$\overline{15}$ & $\begin{array}{c}\text { Slamet } \\
\text { Harjo dkk. } \\
2019\end{array}$ & $\begin{array}{l}\text { Kefektifan LKS Berbasis } \\
\text { STEM untuk Melatih } \\
\text { Keterampilan Berpikir } \\
\text { Kritis Siswa pada } \\
\text { Pembelajaran Fisika SMA }\end{array}$ & $\begin{array}{c}\text { Unnes } \\
\text { Physics } \\
\text { Education } \\
\text { Journal }\end{array}$ & $\begin{array}{c}\text { Menganalisis } \\
\text { efektivitas LKS } \\
\text { dengan } \\
\text { pendekatan STEM } \\
\text { guna } \\
\text { meningkatkan } \\
\text { pemikiran kritis } \\
\text { siswa } \\
\end{array}$ & $\begin{array}{c}\text { Tercapai } \\
\text { efektivitas } \\
\text { LKS dengan } \\
\text { pendekatan } \\
\text { STEM untuk } \\
\text { meningkatkan } \\
\text { pemikiran } \\
\text { kritis siswa } \\
\end{array}$ \\
\hline 16 & $\begin{array}{l}\text { Hannah } \\
\text { Yessi } \\
\text { Priciliaa, } \\
\text { dkk. } 2019\end{array}$ & $\begin{array}{c}\text { Lembar Kerja SiswaPhet } \\
\text { Simulation Berbasis } \\
\text { STEM }\end{array}$ & $\begin{array}{c}\text { Prosiding } \\
\text { Seminar } \\
\text { Nasional } \\
\text { Fisika (E- } \\
\text { Journal) } \\
\text { SNF }\end{array}$ & $\begin{array}{c}\text { Menciptakan LKS } \\
\text { Phet berbasis } \\
\text { STEM }\end{array}$ & $\begin{array}{c}\text { Terpenuhi } \\
\text { pengembangan } \\
\text { LKS Phet } \\
\text { dengan } \\
\text { pendekatan } \\
\text { STEM }\end{array}$ \\
\hline
\end{tabular}

\begin{tabular}{|c|c|c|c|c|c|}
\hline 17 & $\begin{array}{c}\text { Yulia } \\
\text { Pratiwi, } \\
\text { Ramli. } 2019\end{array}$ & $\begin{array}{c}\text { Analisis Kebutuhan } \\
\text { Pengembangan Buku } \\
\text { Siswa Berbasis } \\
\text { Pendekatan STEM pada } \\
\text { Pembelajaran Fisika dalam } \\
\text { Menghadapi Era Revolusi } \\
\text { Industri 4.0 } \\
\end{array}$ & $\begin{array}{c}\text { Jurnal } \\
\text { Penelitian } \\
\text { Pembelajar } \\
\text { an Fisika }\end{array}$ & $\begin{array}{c}\text { Mengembangkan } \\
\text { buku siswa } \\
\text { dengan } \\
\text { pendekatan STEM } \\
\text { guna menghadapi } \\
\text { revolusi industri } \\
4.0 \\
\end{array}$ & $\begin{array}{l}\text { Pengembangan } \\
\text { bahan ajar } \\
\text { berupa buku } \\
\text { siswa berbasis } \\
\text { STEM }\end{array}$ \\
\hline 18 & $\begin{array}{c}\text { Widya } \\
\text { Nessa, } \\
\text { dkk.2017 }\end{array}$ & $\begin{array}{l}\text { Pengembangan Buku } \\
\text { Siswa Materi Jarak Pada } \\
\text { Ruang Dimensi Tiga } \\
\text { Berbasis STEM Problem- } \\
\text { Based Learning Di Kelas }\end{array}$ & $\begin{array}{c}\text { Jurnal } \\
\text { Elemen }\end{array}$ & $\begin{array}{l}\text { Menghasilkan } \\
\text { buku siswa } \\
\text { berbasis STEM } \\
\text { dengan model } \\
\text { PBL }\end{array}$ & $\begin{array}{l}\text { Aplikatif buku } \\
\text { siswa dalam } \\
\text { materi dimensi } \\
\text { ruang tiga } \\
\text { dengan }\end{array}$ \\
\hline
\end{tabular}


Histogram: Jurnal Pendidikan Matematika, 4 (2), 2020 - 363

Fika Ariani Thovawira ${ }^{{ }^{*}}$, Islamiani Safitri ${ }^{2}$,Supartik 3

Nova Nadila Saputri Sitompul 4 ,Ikke Anggriani 5

\begin{tabular}{|c|c|c|c|c|c|}
\hline No & $\begin{array}{c}\text { Penulis } \\
\text { dan } \\
\text { Tahun }\end{array}$ & Topik & $\begin{array}{l}\text { Nama } \\
\text { Jurnal }\end{array}$ & $\begin{array}{c}\text { Tujuan } \\
\text { Penelitian }\end{array}$ & $\begin{array}{c}\text { Hasil } \\
\text { Penelitian }\end{array}$ \\
\hline & & $\mathrm{X}$ & & & $\begin{array}{c}\text { pendekatan } \\
\text { STEM }\end{array}$ \\
\hline$\overline{19}$ & $\begin{array}{l}\text { Taza Nur } \\
\text { Utami, dkk. } \\
2018\end{array}$ & $\begin{array}{l}\text { Pengembangan Modul } \\
\text { Matematika dengan } \\
\text { Pendekatan STEM pada } \\
\text { Materi Segiempat }\end{array}$ & $\begin{array}{c}\text { Jurnal } \\
\text { Matematik } \\
\text { a }\end{array}$ & $\begin{array}{c}\text { Mengidentifikasi } \\
\text { modul matematika } \\
\text { dengan } \\
\text { pendekatan STEM } \\
\text { pada maateri } \\
\text { segiempat }\end{array}$ & $\begin{array}{c}\text { Modul } \\
\text { matematika } \\
\text { materi } \\
\text { segiempat } \\
\text { dengan } \\
\text { pendekatan } \\
\text { STEM teruji } \\
\text { layak } 90 \% \text { uji } \\
\text { coba lapangan }\end{array}$ \\
\hline 20 & $\begin{array}{l}\text { Tri } \\
\text { Mulyania. } \\
2019\end{array}$ & $\begin{array}{l}\text { Pendekatan Pembelajaran } \\
\text { STEM untuk menghadapi } \\
\text { Revolusi Industry } 4.0\end{array}$ & $\begin{array}{c}\text { Seminar } \\
\text { Nasional } \\
\text { Pascasarja } \\
\text { na }\end{array}$ & $\begin{array}{c}\text { Menganalisis } \\
\text { pembelajaran } \\
\text { berbasis STEM } \\
\text { guna menghadapi } \\
\text { revolusi industri } \\
4.0\end{array}$ & $\begin{array}{l}\text { Pembelajaran } \\
\text { STEM dapat } \\
\text { memfasilitasi } \\
\text { siswa dalam } \\
\text { menghadapi } \\
\text { tantangan } \\
\text { revolusi } \\
\text { industri } 4.0\end{array}$ \\
\hline 21 & $\begin{array}{l}\text { Ani Afifah, } \\
\text { dkk. } 2018\end{array}$ & $\begin{array}{c}\text { Persepsi Calon Guru Ipa } \\
\text { Dan Matematika Terhadap } \\
\text { Pembelajaran Berorientasi } \\
\text { STEM }\end{array}$ & $\begin{array}{c}\text { Science } \\
\text { Education } \\
\text { National } \\
\text { Conferenc } \\
\text { e }\end{array}$ & $\begin{array}{l}\text { Mendeskripsikan } \\
\text { persepsi calon } \\
\text { guru mengenai } \\
\text { STEM }\end{array}$ & $\begin{array}{c}\text { Mahasiswa dan } \\
\text { calon guru } \\
\text { memiliki } \\
\text { persepsi yang } \\
\text { baik terhadap } \\
\text { pembelajaran } \\
\text { dengan } \\
\text { orientasi } \\
\text { STEM. }\end{array}$ \\
\hline 22 & $\begin{array}{c}\text { Khusnidar } \\
\text { Daud. } 2019\end{array}$ & $\begin{array}{l}\text { Cabaran guru prasekolah } \\
\text { dalam menerapkan } \\
\text { Pendidikan STEM }\end{array}$ & $\begin{array}{l}\text { Jurnal } \\
\text { Pendidikan } \\
\text { Sains \& } \\
\text { Matematik } \\
\text { Malaysia }\end{array}$ & $\begin{array}{l}\text { Mendeskripsikan } \\
\text { cabaran guru } \\
\text { tentang } \\
\text { pendekatan STEM } \\
\text { pada anak usia } \\
\text { PAUD }\end{array}$ & $\begin{array}{c}\text { Berisi } \\
\text { pertimbangan } \\
\text { tentang } \\
\text { penerapan } \\
\text { pendidikan } \\
\text { STEM pada } \\
\text { siswa } \\
\text { prasekolah } \\
\text { (PAUD). }\end{array}$ \\
\hline 23 & $\begin{array}{l}\text { Edy Setiyo } \\
\text { Utomo, } \\
\text { dkk. } 2020\end{array}$ & $\begin{array}{c}\text { Eksplorasi Penalaran Logis } \\
\text { Calon Guru Matematika } \\
\text { Melalui Pengintegrasian } \\
\text { Pendekatan STEM dalam } \\
\text { Menyelesaikan Soal }\end{array}$ & $\begin{array}{c}\text { Jurnal } \\
\text { Pendidikan } \\
\text { Matematik } \\
\text { a }\end{array}$ & $\begin{array}{l}\text { Mendeskripsikan } \\
\text { tentang aspirasi } \\
\text { calon guru } \\
\text { natematika tentang } \\
\text { pengintegrasian } \\
\text { STEM dalam } \\
\text { pemecahan } \\
\text { masalah }\end{array}$ & $\begin{array}{c}\text { Peninjauan } \\
\text { eksplorasi } \\
\text { calon guru } \\
\text { matematika } \\
\text { terhadap } \\
\text { penyelesaian } \\
\text { soal berbasis } \\
\text { STEM dengan } \\
\text { aplikasi } \\
\text { geogebra } \\
\end{array}$ \\
\hline
\end{tabular}


Histogram: Jurnal Pendidikan Matematika, 4 (2), 2020 - 364

Fika Ariani Thovawira ${ }^{{ }^{*}}$, Islamiani Safitri ${ }^{2}$,Supartik 3

Nova Nadila Saputri Sitompul 4 ,Ikke Anggriani 5

\begin{tabular}{|c|c|c|c|c|c|}
\hline No & $\begin{array}{l}\text { Penulis } \\
\text { dan } \\
\text { Tahun }\end{array}$ & Topik & $\begin{array}{l}\text { Nama } \\
\text { Jurnal }\end{array}$ & $\begin{array}{c}\text { Tujuan } \\
\text { Penelitian }\end{array}$ & $\begin{array}{c}\text { Hasil } \\
\text { Penelitian }\end{array}$ \\
\hline 24 & $\begin{array}{l}\text { Rahmadhan } \\
\text { i, E., \& } \\
\text { Wahyuni, S }\end{array}$ & $\begin{array}{c}\text { Kemampuan Pemahaman } \\
\text { Konsep dan Minat } \\
\text { Mahasiswa dengan } \\
\text { Pendekatan STEM } \\
\text { (Science,Technology,Engi } \\
\text { neering and Mathmatic) }\end{array}$ & $\begin{array}{l}\text { Seminar } \\
\text { Nasional } \\
\text { Pendidika } \\
\quad n \\
\text { Matematik } \\
\text { a (pp. 129- } \\
140)\end{array}$ & $\begin{array}{c}\text { Meningkatkan } \\
\text { pemahaman } \\
\text { konsep dan minat } \\
\text { Mahasiswa } \\
\text { dengan } \\
\text { Pendekatan STEM }\end{array}$ & $\begin{array}{c}\text { Pendekatan } \\
\text { STEM } \\
\text { (Science, } \\
\text { Technology, } \\
\text { Enginnering, } \\
\text { Mathematics) } \\
\text { berupa media } \\
\text { macromedia } \\
\text { flash }\end{array}$ \\
\hline$\overline{25}$ & $\begin{array}{c}\text { Yoana } \\
\text { Nurul Asri. } \\
2018\end{array}$ & $\begin{array}{l}\text { Pembelajaran Berbasis } \\
\text { STEM Melalui Pelatihan } \\
\text { Robotika }\end{array}$ & $\begin{array}{c}\text { Jurnal } \\
\text { Wahana } \\
\text { Pendidikan } \\
\text { Fisika }\end{array}$ & $\begin{array}{c}\text { Mengetahui dan } \\
\text { menganalisis } \\
\text { pembelajaran } \\
\text { dengan } \\
\text { pendekatan STEM } \\
\text { pada pelatihan } \\
\text { robotika }\end{array}$ & $\begin{array}{c}\text { Terdapat } \\
\text { peningkatan } \\
\text { yang baik pada } \\
\text { siswa dalam } \\
\text { merakit robot } \\
\text { dengan } \\
\text { pelatihan } \\
\text { berbasis STEM } \\
\end{array}$ \\
\hline
\end{tabular}

(Sumber: Data Primer, Tahun: 2020)

\section{B. Pembahasan}

Berdasarkan analisis artikel dapat diketahui bahwa implementasi pendekatan STEM berpengaruh terhadap pembelajaran walaupun demikian tetap terdapat tantangan dalam penerapannya.

1. Manfaat Implementasi STEM

Menurut (Supriyatun, 2019),No.6 pada tabel 2 dari hasil pengamatan siswa di SMP N 4 Metro bahwa siswa dapat menganalisis grafik fungsi kuadrat meliputi menyebutkan sifat grafik, menentukan titik balik minimum dan titik balik maksimum. Dengan demikian, dapat dikatakan bahwa siswa telah mengintegrasikan komponen STEM. Ditinjau dari segi sains terdapat hubungan produk air mancur dengan tekanan zat cair. Berikutnya ditinjau dari segi teknologi bahwa pengamatan lintasan dapat divisualkan dengan aplikasi geogebra. Selanjutnya dari segi engineering bahwa proses perancangan air pancur dilakukan dengan memakai botol bekas sebanyak tiga buah. Sehingga kegiatan pembelajaran menurut penelitian ini memberikan siswa keterampilan berpikir dalam menyelesaikan masalah.

Berdasarkan hasil observasi (Rahmadhani \& Wahyuni, 2018), No.24 pada tabel 2, didapatkan bahwa mahasiswa mengalami kesulitan ketika mereka belajar mata kuliah Geometri. Mereka kurang bisa memahami konsep yang abstrak pada materi tersebut, terlihat ketika mereka diberikan soal yang menuntut mereka menggunakan imajinasi 
Histogram: Jurnal Pendidikan Matematika, 4 (2), 2020 - 365

Fika Ariani Thovawira ${ }^{{ }^{*}}$, Islamiani Safitri ${ }^{2}$,Supartik 3

Nova Nadila Saputri Sitompul 4 ,Ikke Anggriani 5

mereka mengalami kesulitan. Hal ini dikarenakan sistem pembelajaran yang masih monoton. Geometri merupakan salah satu mata kuliah di Tadris Matematika (TMA) yang membutuhkan media pembelajaran dalam penyampaian materinya. Karena Geometri merupakan salah satu aspek matematika dengan sifat abstrak. Oleh karena itu, dosen menyampaikan materi dengan menggunakan pendekatan STEM (Science, Technology, Enginnering, Mathematics) berupa media macromedia flash.

Kreativitas mahasiswa dapat meningkat ketika pelaksanaan pembelajaran oleh dosen dan aktivias mahasiswa relevan. Berdasarkan hasil pengamatan terkait keterlaksanaan pembelajaran dosen dan aktivitas mahasiswa yang relevan diperoleh pada bahwa keterlaksanaan pembelajaran oleh dosen dan aktivitas mahasiswa berada pada interval 2,5 $\leq P<3,25$ sehingga kreativitas mahasiswa masuk dalam kategori baik,(Siswanto, 2018), No.3 pada tabel 2.

Selain itu penelitian lainnya dilakukan di SMKN 1 Cianjur pada tahun ajaran 2015/2016 terkait pengaruh STEM dalam pembelajaran matematika, ditunjukkan oleh diagram berikut ini:

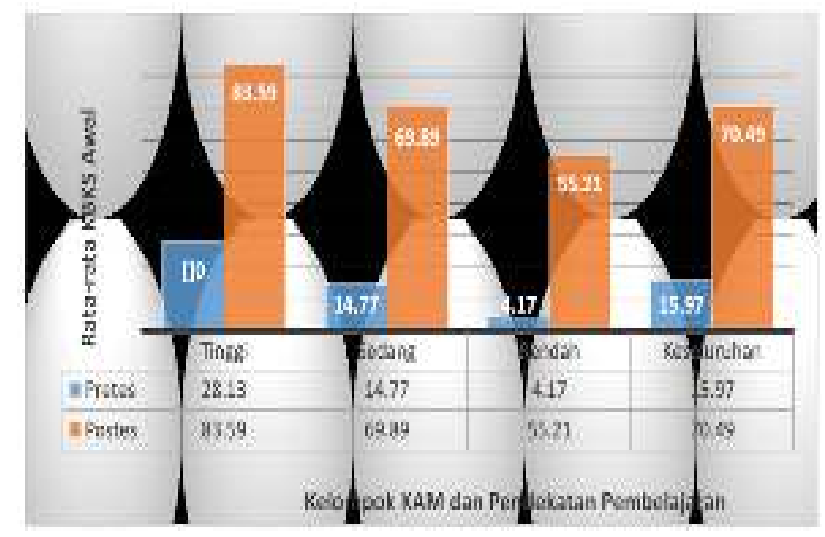

Gambar 1. Diagram Perbandingan Hasil Test Siswa dalam kategori KAM

Hasil penelitian menunjukkan bahwa kemampuan berpikir kreatif termasuk kategori tinggi yaitu dengan skor n-gain 0,77, (Ismayani, 2016),No. 9 pada tabel 2.

Penelitian lainnya dilakukan di Provinsi Banda Aceh, (Muthmainnah, Johar, \& Anwar, 2019),No.12 pada tabel 2, diperoleh hasil tes gambaran denah diambil dari 5 orang perwakilan siswa yang menyatakan bahwa siswa SMPN 2 Banda Aceh telah mampu membuat denah. Pembuatan denah ini dilakukan melalui penerapan dari pendekatan STEM. Dilansir dari penelitian Lowrie, T and Logan, T menyatakan bahwa siswa SMP memahami pembelajaran matematika melalui visual gambar dalam memecahkan masalah dengan sangat baik terhadap representatif matematika yang 
Histogram: Jurnal Pendidikan Matematika, 4 (2), 2020 - 366

Fika Ariani Thovawira ${ }^{{ }^{*}}$, Islamiani Safitri ${ }^{2}$,Supartik 3

Nova Nadila Saputri Sitompul 4 ,Ikke Anggriani 5

bertujuan meningkatkan pengetahuan dan pengalaman diluar sekolahnya. Oleh karena itu, dengan pembelajaran matematika menggunakan gambar melalui pendekatan STEM ini cocok digunakan pada materi perbandingan.

Penelitian dari (Annisa, Hasibuan, \& Damris, 2018),No.2 pada tabel 2, penerapan model PjBL berbasis STEM dalam pembelajaran yaitu pembelajaran berbasis proyek. Hasil penelitian menunjukkan bahwa siswa memiliki keterampilan hard skill dan soft skill sehingga kemampuan berpikir kreatifnya berkembang sesuai kebutuhan kompetensi di abad ke-21, (Sumarni, Wijayati, \& Supanti, 2019), No.10 pada tabel 2.

Kemudian menurut penelitian (Wahyuningsih, Pudyaningtyas, Hafidah, Syamsuddin, Rasmani, \& Nurjanah, 2020), No.5 pada tabel 2, menunjukkan bahwa kegiatan belajar dengan menerapkan model STEAM pada anak usia 5 sampai 6 tahun terbukti dapat meningkatkan minat siswa pada pemecahan masalah. Dalam penelitian ini dapat terlihat model pembelajaran STEAM pada anak usia dini dengan nilai yang signifikan sebesar $\rho \leq 0,05$.

Implementasi STEM pada LKS siswa dapat dilihat dalam penelitian (Pricilia, Budi, \& Astra, 2019),No. 16 pada tabel 2, penelitian ini melakukan inovasi terhadap pengembangan media pembelajaran berbentuk LKPD Phet Simulation pada materi fisika SMA kelas XI terkhususnya pada materi fluida dinamis. Adapun hal-hal yang menjadi acuan yaitu:

Tabel 3. Strategi pencarian literature

\begin{tabular}{lll}
\hline No & Bagian Dalam LKPD & Aspek Keterampilan \\
\hline 1 & A. Pendahuluan & Observe(Mendefenisikan masalah) \\
\hline 2 & B. Hipotesis & New Idea(Mendiagnosis masalah) \\
\hline & C. Alat dan Bahan & Innovation(Merumuskan strategi) \\
& D. Langkah Kerja &
\end{tabular}

\begin{tabular}{llll}
\hline No & Bagian Dalam LKPD & Aspek Keterampilan & \\
\hline \multirow{2}{*}{4} & E. Mengumpulkan Data & Creativity(Menentukan dan & menerapkan \\
& F. & Analisis dan Kesimpulan & strateg) \\
\hline 5 & G. Mengkomunikasikan & Society(Mengevaluasi keberhasilan strateg) \\
\hline
\end{tabular}

(Sumber: Artikel Hannah Yessi Priciliaa, Tahun: 2019)

Berdasarkan penelitian, (Quratulaini, 2019), No.11 pada tabel 2 didapatkan bahwa LKS berbasis STEM efektif digunakan sebagai bahan ajar mata pelajaran IPA. Pada penelitian ini pelaksanaan dilakukan di MTsN 2 Jember dengan perolehan nilai rata- 
Histogram: Jurnal Pendidikan Matematika, 4 (2), 2020 - 367

Fika Ariani Thovawira ${ }^{{ }^{*}}$, Islamiani Safitri ${ }^{2}$,Supartik 3

Nova Nadila Saputri Sitompul 4 ,Ikke Anggriani 5

rata siswa 81,6. Kemudian di MTs Darussalam ditemukan nilai rata-rata sebesar 84,2 dengan kategori sangat tinggi.

Berikutnya hasil penelitian (Nessa, Hartono, \& Hiltrimartin, 2017), No. 18 pada tabel 2 , mengenai buku siswa bahwa dalam materi dimensi tiga berbasis STEM dengan model pembelajaran PBL setelah dianalisis buku siswa berbasis STEM berpotensi terhadap hasil belajar siswa. Berdasarkan pengambilan sampel bahwa 54\% dari 41 siswa sudah mencapai $K K M \geq 75$ yaitu dengan kriteria sebanyak 3 siswa mendapatkan kriteria cukup, 7 siswa mendapatkan kriteria baik dan 12 siswa mendapatkan kriteria sangat baik.

Selanjutnya dalam penelitian yang lain (Asri, 2018), No. 25 pada tabel 2, tentang implementasi pendekatan STEM melalui robotika, diperoleh hasil sebanyak $90 \%$ siswa memahami pemahaman dasar tentang anduino, sinyal analog serta bahasa pemrograman. Selain itu 95\% siswa dapat merakit robot, menginput dan mengkoneksikan bahasa pemrograman ke dalam Bluetooth. Dengan demikian aplikasi STEM juga berperan dalam konsep robotika.

\section{Tantangan Implementasi STEM}

Masih ditemukan guru yang belum mengetahui tentang pendekatan STEM dalam proses pembelajaran, sehingga diasumsikan bahwa guru belum menerapkan pendekatan STEM dalam kegiatan belajar. Oleh sebab itu, perlu dilakukan penelitian untuk mengetahui efektivitas LKS STEM yang berguna untuk melatih keterampilan berpikir kreatif siswa, (Pertiwi, Abdurrahman, \& Rosidin),No.17 pada tabel 2. Dalam (Sukmagati, Yulianti, \& Sugianto, 2020),No. 14 pada tabel 2, hal yang harus diperhatikan dalam pembuatan LKS STEM yaitu tentang penilaian hasil berpikir kreatif pada soal uraian, sebaiknya dibuat rambu-rambu jawaban yang rinci agar memudahkan peneliti dalam pedoman penilaian. Pembuatan soal sebaiknya memperhatikan jumlah soal untuk tiap indikator berpikir kreatif, agar memperoleh komposisi soal yang proporsional,.

Selanjutnya dalam penelitian (Santoso \& Mosik, 2019) terhadap LKS STEM ditemukan bahwa siswa belum mampu menyelesaikan masalah dengan menggabungkan keterampilan berpikir kritis secara terpadu. Ketidakmampuan siswa dalam membedakan konsep materi pembelajaran menjadikan siswa salah menentukan penyelesaian dari permasalahan yang diberikan. Dengan demikian tantangan implementasi STEM dalam kasus ini yaitu terkait dengan pemahaman konsep.

Dalam (Daud, 2019),No.22 pada tabel 2, terkait persepsi calon guru terhadap penerapan STEM pada pembelajaran, bahwasanya untuk mempersiapkan siswa menghadapi tantangan globalisasi perlu pembelajaran berorientasi STEM yang berbasis 
Histogram: Jurnal Pendidikan Matematika, 4 (2), 2020 - 368



Nova Nadila Saputri Sitompul 4 ,Ikke Anggriani 5

proyek. Menurut Permanasari (2016), pembelajaran berorientasi STEM bisa menggunakan salah satu metode yaitu metode Problem Based Learning (PBL). Dengan metode ini diharapkan dapat memberi kesempatan bagi siswa dalam menerapkan pengetahuan yang dimilikinya untuk menyelesaikan permasalahan. Dengan metode Project Based Learning (PjBL) dapat mendorong siswa untuk memiliki pemikiran rasional, kritis, dan sistematis sehingga siswa mampu menyelesaikan permasalahan berbasis proyek(Hubbard, 2012).

Menilik dari penjabaran manfaat dan tantangan implementasi STEM di Indonesia mendapatkan kategori cukup baik. Pembelajaran STEM diterapkan pada pembuatan LKS, buku siswa dan pembelajaran serta mampu meningkatkan literasi matematis siswa. Pada sistematic review ini menunjukkan bahwa implementasi pendekatan STEM di Indonesia memiliki pengaruh yang cukup baik terhadap terhadap cara berpikir kreatif siswa, LKS, buku siswa dan menghadapi revolusi industri 4.0 , literasi matematis dan implementasi STEM dengan robotika, dan juga persepsi guru terhadap pembelajaran STEM.

\section{IV.KESIMPULANDAN SARAN}

\section{A. Kesimpulan}

Dari 56 artikel yang cocok dengan topik penelitian, kemudian dilakukan screening terkait kesamaan judul artikel. Setelah proses screening terdapat 30 artikel dengan judul yang sama. Selanjutnya 30 artikel discreening berdasarkan kesesuaian syarat dengan kriteria inklusi dan kriteria eksklusi maka diperoleh 25 artikel .Berdasarkan observasi hasil penelitian yang telah dilakukan di lapangan, dari aspek pelaksanaan pembelajaran Fisika, diperoleh bahwa pendidik sudah mengarahkan dan menemukan konsep namun belum optimal. Masih kurangnya minat belajar siswadan kurang dalam mengerjakan soal-soal latihan. Pendidik mengetahui pembelajaran STEM, tetapi belum optimal dalam menerapkan dalam pembelajaran.

Pada aspek penggunaan bahan ajar Fisika, bentuknya masik kurang variatif, akibatnya siswa hanya terfokus pada buku ajar yang menjadi pegangan pendidik saat mengajar (Festiyed, 2015). Bahan pembelajaran yang tersedia hanya menekankan pada representasi matematis dan belum memuat pendekatan sesuai dengan pembelajaran Fisika. Bahan ajar yang ada belum seutuhnya dapat menjadikan siswa untuk aktif dan mandiri. Pemilihan bahan ajar yang tepat merupakan suatu acuan untuk menentukan keberhasilan dalam pembelajaran. Guru seharusnya dapat mengetahui bahan ajar mana yang cocok digunakan untuk siswadalam mencapai tujuan dan terlaksananya proses pembelajaran dengan baik. Oleh karena itu, diperlukan adanya pengembangan bahan ajar 
Histogram: Jurnal Pendidikan Matematika, 4 (2), 2020 - 369

Fika Ariani Thovawira ${ }^{*}$, Islamiani Safitri ${ }^{2}$,Supartik 3

Nova Nadila Saputri Sitompul 4 ,Ikke Anggriani 5

dengan pendekatan yang dapat mendukung proses pembelajaran berbasis pendekatan STEM.

Pemecahan masalah, berpikir kritis, berpikir kreatif, dan menganalisis adalah kriteria keterampilan yang dibutuhkan guna menghadapi kemajuan teknologi dan pendidikan.Hal yang mendukung pengembangan kemampuan ini ialah dalam mata pelajaran fisika dan matematika. Namun beberapa fakta di lapangan terlihat bahwa pelajaran matematika dan fisika cenderung membosankan dan pasif. Konsep pembelajaran akan lebih dipahami jika siswa aktif dan melakukan aktivitas yang menarik perhatian siswa seperti media yang dapat menarik perhatian mereka. Selain itu peran teknologi juga sangat diperlukan dan diaplikasikan dalam pembelajaran

\section{B. Saran}

Pentingnya peran guru dalam mengembangkan literasi STEM. Oleh karena perilaku guru dipengaruhi oleh individu, sosial, lingkungan, dan kebijakan sehingga memberikan dampak pada keputusan guru tentang pendekatan pedagogis yang akan diadopsi dalam pembelajaran (Elder, dkk., 2007). Untuk itu, sebagai praktisi sangatlah penting bahwa guru dan calon guru dilatih dalam menerapkan pembelajaran berorientasi STEM. Penerapan pendekatan STEM dalam pembelajaran diharapkan dapat membekali siswa dengan berbagai keterampilan yang dibutuhkannya dalam menghadapi persaingan di era revolusi indutri 4.0. Begitu juga dengan pengintegrasian pendekatan STEM didalam buku siswa ini, dapat menjadikan pembelajaran menjadi lebih bermakna.

Tidak hanya itu pada saat pelaksanaan praktikum siswa diharapkan agar tidak berpatokan pada pengarahan guru saja, jadi siswa harus menemukan sendiri hal-hal yang diperlukan dalam kegiatan praktikum disebut juga dengan discovery learning.Tuntutan pada kurikulum adalah student center dalam kenyataan di lapangan belum terkoordinasi seluruhnya.

\section{DAFTAR PUSTAKA}

Annisa, R., Hasibuan, M. H., \& Damris, M. (2018). Peningkatan Kemampuan Berpikir Kreatif Siswa dengan Menggunakan Model Project Based. Jurnal of the Indonesian Society of Integrated Chemistry, 42-46.

Asri, Y. N. (2018). Pembelajaran Berbasis STEM Melalui Pelatihan Robotika. Jurnal Wahana Pendidikan Fisika, 74-78.

Daud, K. M. (2019). Cabaran guru prasekolah dalam menerapkan Pendidikan Stem. Jurnal Pendidikan Sains \& Matematik Malaysia , 25-34. 
Histogram: Jurnal Pendidikan Matematika, 4 (2), 2020 - 370

Fika Ariani Thovawira ${ }^{*}$, Islamiani Safitri ${ }^{2}$,Supartik 3

Nova Nadila Saputri Sitompul 4 ,Ikke Anggriani 5

Ismayani, A. (2016). Pengaruh Penerapan STEM Project-Based Learning terhadap Kreativitas Matematis Siswa SMK. Indonesian Digital Journal of Mathematics and Education , 264-272.

Istiqomah, A. (2019). Implementasi Strategi I-STEM (Islamic, Science,Technology, Engineering, And Mathematics) pada Pembelajaran IPA Terhadap Kemampuan Berpikir Kreatif dan Karakter Konservasi Siswa. Semarang: Universitas Negeri Semarang.

Muthmainnah, Johar, R., \& Anwar. (2019). Kemampuan Siswa SMP Membat Denah melalui Pendekatan Science, Technology, Engineering, Mathematics (STEM) Pada Materi Perbandingan. Jurnal Ilmiah Mahasiswa Pendidikan Matematika , 73-80.

Nessa, W., Hartono, Y., \& Hiltrimartin, C. (2017). Pengembangan Buku Siswa Materi Jarak pada Ruang Dimensi Tiga Berbasis Science, Technology, Engineering, and Mathmatics (STEM) Problem-Based Learning di Kelas X. Jurnal Elemen , 1-14.

Octaviyani, I., Kusumah, Y. S., \& Hasanah, A. (2020). Peningkatan Kemampuan Berfikir Kreatif Matematis Siswa. Journal on Mathematics Education Research , 10-14.

Pertiwi, R. S., Abdurrahman, \& Rosidin, U. (n.d.). Efektivitas LKS STEM untuk Melatih Keterampilan Berpikir Kreatif Siswa. Universitas Lampung, , 11-19.

Pricilia, H. Y., Budi, E., \& Astra, I. M. (2019). Lembar Kerja SiswaPhet Simulation Berbasis STEM. Seminar Nasional Fisika (pp. 313-318). Jakarta: Universitas Negeri Jakarta.

Quratulaini. (2019). Pengembangan Lks Ipa Berbasis STEM (Science,Technology, Engineering,Mathmatic) untuk Meningkatkan Kemampuan Berpikir Kreatif dan Hasil Belajar Siswa SMP/MTs. Jember: Universitas Jember.

Rahmadhani, E., \& Wahyuni, S. (2018). Kemampuan Pemahaman Konsep dan Minat Mahasiswa dengan Pendekatan STEM (Science,Technology,Engineering and Mathmatic). Seminar Nasional Pendidikan Matematika (pp. 129-140). Takengon: STAIN GAJAHPUTIH.

Santoso, S. H., \& Mosik, M. (2019). Kefektifan LKS Berbasis STEM (Science, Technology, Engineering and Mathematic) untuk Melatih Keterampilan Berpikir Kritis Siswa pada Pembelajaran Fisika SMA. Unnes Physics Education Journal, 248-253. 
Histogram: Jurnal Pendidikan Matematika, 4 (2), 2020 - 371

Fika Ariani Thovawira ${ }^{{ }^{*}}$, Islamiani Safitri ${ }^{2}$,Supartik ${ }^{3}$ Nova Nadila Saputri Sitompul 4 ,Ikke Anggriani 5

Sari, R. H. (2017). Pengaruh Implementasi Pembelajaran STEM Terhadap Persepsi, Sikap, dan Kreativitas Siswa. PROSIDING SEMINAR NASIONAL MIPA III (pp. 416-420). Langsa-Aceh: Universitas Syiah Kuala.

Siswanto, J. (2018). Keefektifan Pembelajaran Fisika dengan Pendekatan STEM untuk Meningkatkan Kreativitas Mahasiswa. Jurnal Penelitian Pembelajaran Fisika, 133-137.

Sukmagati, O. P., Yulianti, D., \& Sugianto, S. (2020). Pengembangan Lembar Kerja Siswa (LKS) Berbasis STEM (Science, Technology, Engineering, and Mathematics) untuk Meningkatkan Kemampuan Berpikir Kreatif Siswa SMP. Unnes Physics Education Journal , 18-26.

Sumarni, W., Wijayati, N., \& Supanti, S. (2019). Kemampuan Kognitif dan Berpikir Kreatif Siswa Melalui Pembelajaran Berbasis Proyek Berpendekatan STEM. Jurnal Pembelajaran Kimia, 18-30.

Supriyatun, S. E. (2019). Implementasi Pembelajaran Sains,Teknologi,Engineering dan Matematika (STEM) pada Materi Fungsi Kuadrat. Jurnal Matematika Ilmiah STKIP Muhammadiyah Kuningan , 80-87.

Wahyuningsih, S., Pudyaningtyas, A. R., Hafidah, R., Syamsuddin, M. M., Rasmani, U. E., \& Nurjanah, N. E. (2020). Efek Metode STEAM pada Kreatifitas Anak Usia 5-6 Tahun. Jurnal Obsesi : Jurnal Pendidikan Anak Usia Dini , 295-301. 